\title{
EFFECT OF GOVERNMENTAL ANNOUNCEMENT AND DECISIONS DURING COVID-19 ON INDONESIAN SECTORAL INDEXES
}

\author{
Irshad Adriatama ${ }^{1 *}$, Raden Aswin Rahadi ${ }^{2}$ \\ 1,2Institut Teknologi Bandung, Bandung, Indonesia



\begin{abstract}
Stock prices around the world began to fall after COVID-19 pandemic spreads. This paper analyzed the historical data of several composite index from different sectors in Indonesia during the period of COVID-19 pandemic. It took notes of important events during pandemic such as: first confirmed case, first death, workfrom-home policy implementation, and other events. It saw whether these events affected the index price by analyzing the abnormal return of the stock prices during those events. It hypothesized that different event would bring different reaction to different sectors. It found that different sectors reacted differently towards policy implementation and announcements, sectors such as consumer goods and infrastructure managed to gained profit while sectors such as property and mining suffered a loss.
\end{abstract}

Keywords: COVID-19, pandemic, stock market, abnormal return.

\section{Introduction}

When talking about disease that can infect people, pandemic is the worst thing that can happen. When epidemic spreads and become global that is when a pandemic begin. Pandemic begin to appear as human begin to create communities that made epidemic such as malaria, tuberculosis, and influenza starts to appear (History.com, 2020), COVID-19 is the most recent example of this pandemic as it has gone beyond the country borders and had become global. In order to counter this pandemic, governments all around the world had begun to implement various safety regulations to ensure the livelihood of their citizens. Australia implemented a quarantine for those who came back from abroad, as well as implementing social distancing and closing public places such as beaches (Kelly, 2020), UK starts to encourage their people to stay at home (Smyth, 2020), and other countries had also started to implement their safety measures. Policies such as work-from-home policy may bear heavy implications to companies themselves as well as their employees, which ultimately translates to the whole economy itself. During March 2020, United States stock market had stopped their trading activities for four times within ten days. Not only US, stock markets in Europe and Asia had also plummeted. FTSE dropped more than $10 \%$ on 12 March, and Japan stock market had plummeted more than $20 \%$ from its highest position (Zhang, Hu, \& Ji, 2020). By this fact, it can be seen that the world is undergoing some changes, in this uncertain situation government as well as other external factors might affect the economy more than expected. This holds true for Indonesia as well. In
Indonesia the stock price had been gone off recently following the COVID-19 outbreak. The government had also imposed several regulations as well as giving important announcements within the period of several months that affects the way people do things, and thus this research aims to see whether these real-life events affect the stock price or not.

Indonesia is chosen as the observation target for this research due to the fact that Indonesia has a potential to become one of the largest economy in the world, Indonesia also holds the most number of unicorns in Southeast Asia, Indonesia had been increasing in its venture deals, not to mention the local government is also spending its resource on improving infrastructure in order to create an ease of connectivity between land, air, and sea (Nadhifah, 2020). Thus making Indonesia an observation target since Indonesia is still considered as an emerging country.

Our objective within this research is to find out whether real-life events during this pandemic can affect the return of existing stocks by analyzing the abnormal returns on sectoral index that might occur during the time that event happened, such as first case of COVID-19 in Indonesia, first death by COVID-19 in Indonesia, as well as other important dates such as the social distancing regulation date, and as of the latest the travel-ban regulation date. This research will be focused on the capital city of Indonesia, Jakarta for the benchmark of the social distancing regulation date.

This paper contributes to the ever expanding study of finance, as well as a study on the impact of pandemic towards the financial markets. Similar studies had also been conducted such as seeing the impact of terrorism towards financial market as well as 
its financial implication previous research includes Chesney, Reshetar, and Karaman (2011), Corbet, Gurdgiev, and Meegan (2018), Karolyi, (2011), and Nikkinen and Vähämaa (2010), as well comparing it with the natural disaster impact towards financial market (Brounen \& Derwall, 2010). In order to contribute to the growing literature regarding COVID19 , this paper focuses on studying the effect of events in form of governmental announcements as well as governmental regulations and translates it into the effect of those events towards the stock price, a topic which has not been discussed yet.

Pandemic is something that in terms of frequency rarely happens, thus new researches can help us in understanding more about what will happen when a pandemic occurs. Some interesting research regarding pandemic and its financial implications such as relationship between pandemic and banking (Lagoarde-Segot \& Leoni, 2013), to as recent as Baker et al. (2020) which discuss COVID-19 impact to the stock market. This what makes this research a unique one, considering that the result might be different from what existing research had already found. Thus, it is hoped that the result from this paper is something that had not been studied before and can serve as an addition to the existing literature regarding financial markets in times of pandemic. The period of this study spans from the start of the pandemic in Indonesia which is during March of 2020, until April 2020 where several implementations and events had happened in Indonesia during that time span.

The method used to see the effect on the stock price is by calculating the abnormal return of each composite index price during the date where the event happened, to make it possible to see the difference, few days before and after the event will also be analyzed to make sure whether there are differences or not. The expected return for indexes for calculating the abnormal return will be calculated using the CAPM formula. This research will also calculate the cumulative abnormal return (CAR) measured over the periods. This similar method of testing is used by Brounen and Derwall (2010) to see the effect of terrorism to stock price (Brounen \& Derwall, 2010). This research will be an application of that model should it is used within the context of pandemic. There are bound to be difference between the result and Brounen and Derwall's (2010) result since pandemic is not a one-time event but rather a long time event that might happen for an unpredicted amount of time, several events are used in this research to be able to capture the whole condition of the pandemic as a whole, to see whether events during this pandemic period can affect the price or not.
In this paper, it is assumed that not only in Indonesia but every other country also suffers from this kind of situation although the exact reason may vary and may differs per country. In case of Indonesia, it is assumed that policies and knowledge given by the government had become the main factor on why the price of the stock fluctuates. In order to address the assumption on this paper, there is a need to note the question within this paper. The main research question within this research paper is will there be any difference between sectors in terms of amount of price affected by those events or not.

The limitation of this research is that this research is conducted during the period of COVID-19, when the pandemic is still ongoing. With the pandemic still ongoing, there might be other things that will happen in the future that might affect the result of this research. It would be better should this research is conducted once again with different constraints and variables since when this pandemic is over people should be able to look at things in more detail since everything had already happened. Also, this research did not count for any possible confounding bias. This research sees an event as a single individual event that happened at one time, there might be influence from another event that might reflect on the result but is not mapped due to the close date between one event to another within this research.

The remainder of the paper is structured as follows. Section 2 reviews the literature and develops the hypotheses. Section 3 describes the data and research method used to conduct this research. Section 4 presents the timeline of this research; and Section 5 closes with a summary of this research proposal.

\section{Pandemic in Context of Finance}

Pandemics can be described as a large-scale outbreak of infectious disease with potential of increasing mortality rate everywhere around the affected area as well as causing economic, social, and political disruptions. Not only that, previous research by Madhav et al. (2017) showed that pandemic could also cause behavioral changes within individual, sparks tensions between individuals which could result in rising of violent behaviors as well as tension between government and its citizens.

Pandemic affects many aspects and areas, starting from the obvious health impact to everyone in the world, to the change in economic and financial world itself. One example regarding pandemic implication towards the economy, one study finds that when people are experiencing symptoms within the shadow 
of death during this pandemic that requires to be treated, those said patients may withdraw their investments in order to pay for their own or even their relatives care. And when these withdrawals happen in a large scale, the bank reserves will be drained which implies that by the rise of a pandemic, the likelihood of a general banking collapse increases. The withdrawal rate may exceed bank reserve, which may cause bank to default (Lagoarde-Segot \& Leoni, 2013).

Before the COVID-19 pandemic happened, this world has been through several pandemics, and researchers have also been studying the effects of pandemic towards the economics during these past pandemics. One of the most famous pandemic is the Spanish flu. During the Spanish flu pandemic, the Dow Jones fell around $10 \%$ in a few months during the peak of the pandemic, and soon regain its momentum back when the pandemic is over. The Spanish flu that started in 1918 and lasted until the end of 1920 infected around 500 million people or around $25 \%$ of the population at the time. The estimated death from this pandemic is between 17-50 million people. The most interesting fact at this time is that some sales actually increased within this period of pandemic (Lango, 2020). However, the Spanish flu started in 1918, the last year of the World War I, which makes it quite difficult to differentiate which one was the impact of the Spanish flu and the impact of the war towards the economy itself, and due to the World War I, there are not many things that Spanish flu can disrupt, because it has already been disrupted in the first place due to the war, this is probably what causes the impact to be relatively small as the stock market response differs a lot when COVID-19 occurs compared to what happened back then during the Spanish flu pandemic. The Dow Jones dropped over 2000 points within 4 days out of the fear of COVID-19, while back then the market was relatively unaffected by the Spanish flu during the start of the pandemic itself (Dure, 2020; Taylor, 2020). Burdekin (2020) also found that the European and US stock markets reacted significantly and negatively towards the death rate during the Spanish flu period, indicating that the death rate affected the stock market significantly compared to what was happening now with the COVID-19, however as mentioned on previous literature regarding Spanish flu. The Spanish flu happened during the end of World War I, where the supply-chain were disrupted at that time, making it hard or even impossible to discern whether the stock market responded to the World War or to the pandemic itself (Burdekin, 2020; Dure, 2020; Taylor, 2020).

Another relatively recent case of outbreak was the SARS outbreak. SARS did not affect markets until the
Chinese authorities reported the outbreak to the WHO. During this period, the China Index underperformed compared to other global indexes. All S\&P 500 sectors declined during this outbreak period. The sector that took the most damage was the information technology, financials, and communication services, while in China the biggest loser was travel, retail, and leisure industries. SARS is estimated to cause US $\$ 40$ billion of economic loss as well as $0.1 \%$ hit on the world GDP (Dure, 2020). However, compared to SARS outbreak, COVID-19 outbreak have more effect on the Chinese stock market. Chinese equity valuations suffered from a 5\% loss during the $10^{\text {th }}$ trading day after the COVID19 outbreak, while it took around 20 days to reach that point when SARS occurred. However, the Chinese stock begin to regain momentum faster during COVID-19 compared to when SARS happened. Emerging Asian stock markets outside China also suffered the same greater initial loss during the COVID-19 outbreak compared to when SARS happened, this might be caused by the global economic integration that is stronger now compared to back then (Avalos \& Zakrajšek, 2020). Despite its seemingly huge impact, another interesting research found that the impact of SARS on the stock markets only affects several stock markets instead of the whole affected countries stock markets. It is found that SARS affects China and Vietnam the most, while Canada, Hong Kong, Indonesia, Philippines, Singapore, and Thailand have no negative impact during the same period of various announcement regarding SARS compared to China and Vietnam who suffered from the negative impact of the SARS (Nippani \& Washer, 2004).

Another well-known outbreak was the Avian Influenza. Not only that the Avian Influenza caused a significant loss in the agricultural sector due to the change in prices as well as consumer confidence and trade volumes. It is also found that daily reported number of avian influenza cases impacts the Avian Influenza Sector Index closing price, while there is no significant association with opening price. In contrast to this, the Shanghai Composite Index which had the opening price affected by the daily reported case instead of the closing price. As for the Chinese Traditional Medicine Sector Index, Biological Product Sector Index, and the Biomedicine Sector Index, the daily reported case significantly affects the opening and closing price (Jiang et al., 2017).

However, the impact of the actual disease does not really hit the world GDP significantly. Mensbrugghe, Timmer, and Burns (2006) made an analysis during the previous avian influenza outbreak in Vietnam in 2004, when the disease was enzootic it would 
only costs the world GDP by $0.1 \%$ while when divided into regional GDP, the highest cost was $0.7 \%$. This shows us that should the disease does not spread from human to human, while it does have some impact, it does not show that much of a change. However, the case is quite different when the case is a human pandemic. Mensbrugghe et al. (2006) also created a simulation based on previous flu data by noting the Hong Kong flu as mild scenario, Asian flu as the moderate scenario, and Spanish flu as the severe scenario. It is found that the highest respective cost for regional GDP is $2.1 \%, 4.8 \%$, and $9.9 \%$, with the cost to the global GDP is $0.7 \%, 2 \%, 4.8 \%$ respectively for each scenario. Developing countries will receive the most severe blow due to higher population density as well as poverty levels (Mensbrugghe et al., 2006).

Based on these past literatures during past outbreaks, it can be seen that while the disease itself had an effect towards the economic itself, these disease does not leave a significant impact as past literatures mentioned that they managed to gain their momentum back when the disease is over. However, just as Avalos and Zakrajšek (2020) stated the global economic integration was stronger now compared to back then, not to mention the advancement of the technology, therefore COVID-19 might bring a different result compared to the past pandemics.

Now, for the COVID-19 pandemic that the world is experiencing right now, this is by far the biggest crisis that the world has ever experienced with no other previous disease including "Spanish Flu" that had this big of an impact to the world in many areas. In the United States, the volatility level of stock market had rival some of the biggest crisis on the United States such as "The Great Depression", as well as "Global Financial Crisis", and with coronavirus still an ongoing thing with no certainty for the future, it might surpass the volatility level of the "Black Monday" and "The Great Crash" as well (Baker et al., 2020).

During March 2020, United States stock market had stopped their trading activities for four times within ten days. Not only US, stock markets in Europe and Asia had also plummeted. FTSE dropped more than $10 \%$ on 12 March, and Japan stock market had plummeted more than $20 \%$ from its highest position (Zhang et al., 2020). These economic declines are comparable if not worse compared to the global Great Recession of 2008-2009, opening the posibillity of not only major deaths but also major global economic contraction (Barro, Ursúa, \& Weng, 2020).

This paper offers a contribution to the existing literature by analyzing the effect of governmental announcement and implementations towards the stock price of different sectors in Indonesia to the response of each sectors by looking at the abnormal return of stock that might arise from those announcements as well as implementations. Indonesia is considered as one of the emerging stock markets, which are more vulnerable towards uncertainty of pandemic and epidemic compared to developed market stocks (Salisu, Sikiru, \& Vo, 2020), this paper is designed to be able to find out how does Indonesian sectors performs in this situation.

\section{COVID-19 Studies}

This paper analyzes the economic outcome of COVID-19 across different industry in Indonesia, previous research in this area had analyzed the effect of COVID-19 among different sector (Gu, Ying, Zhang, \& Tao, 2020; He, Sun, Zhang, \& Li, 2020), not only COVID-19, previous literature also have shown the effect of an event to stock prices for example the effect of SARS towards the stock prices (Chen, Jang, \& Kim, 2007), the effect of terrorism towards stock price (Brounen \& Derwall, 2010; Chesney et al., 2011; Nikkinen \& Vähämaa, 2010).

Previous research related to COVID-19 and its financial implications includes the effect of governmental intervention (Ashraf, 2020a; Zhang et al., 2020), firms respond toward COVID-19 (Gu et al., 2020), country response towards COVID-19 (Phan \& Narayan, 2020), impact towards returns (Al-Awadhi, Alsaifi, Al-Awadhi, \& Alhammadi, 2020; Ashraf, 2020a, 2020b), stock price reactions (Phan \& Narayan, 2020; Salisu et al., 2020), as well as the choice of alternative assets in this pandemic (Ali, Alam, \& Rizvi, 2020).

Previous literature found that social distancing measures implemented by the government have a direct negative effect on the stock prices and an indirect positive effect to reducing COVID-19 cases, and government announcement that raises public awareness, quarantine policies, as well as support had resulted in positive market returns and shows that social distancing saves people lives in return of giving a burden to the economic activities (Ashraf, 2020a).

Firms in China also shown to receive a shock by looking at the electricity consumption during the pandemic period showing a drop in economic activities, and the impact of COVID-19 differs from one sector to another, industries such as transport, tourism, are constrained while industries such as manufacturing and mining suffered from a supply shock (Gu et al., 2020), although this contrasts with another finding that in China it is shown that manufacturing industry 
managed to gain a positive return due to the opportunities that the pandemic had brought them such as the mass production of masks, as well as medical equipment (He et al., 2020) which is further clarified by another finding that shows the medicine manufacturing sector performed better during this period of pandemic (Al-Awadhi et al., 2020).

Another research also shows that COVID-19 had incited reactions from the governments out of fear of the unknown and shows that government overreacts during the early stage of the pandemic, but as information comes in government will be able to correct their reactions, and what policies works best for each country differs from one to another (Phan \& Narayan, 2020). During this COVID-19, investment assets also showed a decline, assets such as bitcoin suffered from a big negative return (Ali et al., 2020), while gold and soybean commodity seems to be the least volatile investment asset during this pandemic period (Ali et al., 2020; Ji, Zhang, \& Zhao, 2020). It is also found that emerging stock markets are more vulnerable towards uncertainty off pandemic and epidemic compared to developed stock markets as developed stock markets provides better hedging measures (Salisu et al., 2020). Not only short term, COVID19 also might cause an impact towards permanent volatility of the international stock markets, government must be able to face what is coming after this pandemic is over as it might leave a permanent impact on the market (Bai, Wei, Wei, Li, \& Zhang, 2020).

This paper analyzes the economic outcome of COVID-19 across different industry in Indonesia, previous research in this area had analyzed the effect of COVID-19 among different sector (Gu et al., 2020; He et al., 2020), not only COVID-19, previous literature also have shown the effect of an event to stock prices for example the effect of SARS towards the stock prices (Chen et al., 2007), the effect of terrorism towards stock price (Brounen \& Derwall, 2010; Chesney et al., 2011; Nikkinen \& Vähämaa, 2010). Previous research related to COVID-19 and its financial implications includes the effect of governmental intervention (Ashraf, 2020a; Zhang et al., 2020), firms respond toward COVID-19 (Gu et al., 2020), country response towards COVID-19 (Phan \& Narayan, 2020), impact towards returns (Al-Awadhi et al., 2020; Ashraf, 2020a, 2020b), stock price reactions (Phan \& Narayan, 2020; Salisu et al., 2020), as well as the choice of alternative assets in this pandemic (Ali et al., 2020). On top of that, there are also emerging literatures within Indonesia regarding the COVID-19 pandemic which includes the impact of COVID-19 towards Indonesian economy (Susilawati, Falefi, \&
Purwoko, 2020), the effect of physical distancing towards anxiety (Ardan, Rahman, \& Geroda, 2020), as well as challenges within the policy implementation during COVID-19 (Setyawan \& Lestari, 2020). Our novelty is that this research will be able to give an insight on how events can bring different kind of shocks towards the stock prices of different industries.

\section{Events}

A study which simulates the effect of pandemic towards GDP in UK founds that pandemic would reduce GDP by $0.3 \%, 0.4 \%$ and $0.6 \%$ in three disease scenario based on its scale. However, the effect of the pandemic itself is smaller compared to the effect of disease mitigation policies such as school closures as well as absence from work to avoid infection. Combining those two factors with the pandemic brings the percentage of $1.1 \%, 1.3 \%$, and $1.4 \%$ for the same three scenarios. This shows that the greatest concern for the macroeconomic is not the disease itself, therefore it is out of importance that a balance between these policies are needed to ensure that the worse did not happen. Government must be able to find the balance between "social distancing" and "doing things as usual" (Smith, Keogh-Brown, \& Barnett, 2011).

Baker et al. (2020) proposed that there were three potential answer on why COVID had reached the level of severity that not any previous pandemic achieved. First potential answer is due to the severity of the virus itself, regarding how easy it spreads as well as its high mortality rate. Second potential answer is regarding how information is easier to spread now compared to then. Information regarding COVID-19 quickly spreads and raises many reactions from people that including those who triggers the volatility of the market. And lastly the third possible answer is that the border and the interconnectedness of the modern economy cannot be compared to then. Nowadays people travels around country for work as transportation media had become more advanced to what it was once. Companies had also begin to establish partnership all around the world, securing suppliers and vendors from another part of the world. By establishing a global supply chain, it is understandable that it will spark the change in price when speaking of our current situation.

But despite all those possible answers, while it is explainable with those three answer, it still does not explain the anomaly of the situation the world are in right now with the stock price keeps on plummeting, and when comparing with other pandemic data which is the "Spanish Flu" which did not trigger any jump within stock price even months after it happened. 
Therefore, there might arise the need to address the policy established during this period of pandemic itself, current containment efforts such as social distancing is much more intensive compared to back then which can impact the modern economy badly due to reasons stated above (Barro et al., 2020).

COVID-19 had brought fear into people, including the governments who reacted to that fear in form of safety measures and policies, but when the government reacts, other citizens do not have many choices as they can only react to what their government implements (Phan \& Narayan, 2020). Thus, the best answer on why COVID-19 have a great impact on the economy is due to the policies all over the world established as a response of COVID-19 (Baker et al., 2020).

Although the policies established so far such as social distancing policies, travel restriction policies, and other policies are meant to protect us from the danger of pandemic, it is because of these policies as well that the economy had turn in for the worse. During recent study, it is found that while social distancing can reduce the number of infection case, it have a direct negative effect on stock prices, this implies that while social distancing can save lives of many, there is a large cost caused by the reduced economic activity (Ashraf, 2020a). While it might seem unethical, this had created some kind of "trade-off" between the choice of saving lives or saving material goods (Barro et al., 2020).

This is what lead us to investigate these policies in form of "events", the day where the policy is implemented becomes an event that will be investigated in order to see whether there are impacts that were made from the establishment of these policies or not. In addition to those policies, important dates where information are disclosed to the public will also be categorized as events to make the research more diverse. While previous literatures had studied regarding stock prices fluctuation as well as sectoral responses, this research will give a contribution to this field of research by adding an event study during the period of pandemic to see whether different kind of event will be received differently by different sector or not. With that in mind, now let us discuss about the tools used in this research.

This paper is using an event study method where a specific event is analyzed in order to get more information. The objective of an event study within this context is to see the extent where investor can gain abnormal return from stock due to events that carries new information (Sorescu, Warren, \& Ertekin, 2017). This implies to Fama's (1970) research regarding semistrong efficient market hypothesis where the stock price will reflect all publicly available information and will change to reflect new information should a new information is available. By using this event study method, the changes in stock price caused by the introduction of a new information will be available, in this case, that information came in form of events, thus the event study method is used for this research.

\section{Abnormal Returns}

In this research, sectoral index abnormal return will be used as a tool to measure changes in stock price. Due to this fact, there is a need to understand about what is abnormal return as well as how to calculate it. Abnormal return is used to describe the difference between actual return and expected return. In the efficient market hypothesis, an efficient market manager cannot achieve an abnormal or excess return. On an efficient market, any information released before should have no effect on abnormal returns because all its influence should have been felt, an efficient market would have already incorporated previous information in price (Ross, Westerfield, \& Jaffe, 2012).

A study finds out that firms in an industry with many competitors as well as firms within regulated industries earn higher abnormal returns compared to others (Muradoğlu \& Sivaprasad, 2012). Abnormal returns are an important factor in determining a portfolio risk-adjusted performance compared to the market. Abnormal return can help identify a portfolio manager's skill as well as to illustrate whether investor received a compensation worth of their investment risk or not (Barone, 2019).

To calculate an abnormal return, there is a need find the expected return. Expected return is a return that investor expects their stock to earn over time. Because its nature as a merely expectation, the actual return might differs compared to the expected return. An expectation might just be taken by simply seeing its past performances. Expectation might also come from an analysis of a firm's prospect, or even from an insider information (Ross et al., 2012).

In order to find this expected return, CAPM is often used to calculate the expected return. CAPM had the implication that expected return of a security is linearly related to its beta. Because of the average market return is higher than the average risk-free rate over a period of time, the CAPM formula implies that the expected return on a security is positively related to its beta in which beta is the measure of volatility (Ross et al., 2012).

\section{Research Hypothesis}

Previous literature have mentioned that the shock differs between one sector to another (Al-Awadhi et 
al., 2020; Gu et al., 2020; He et al., 2020). Therefore, it is hypothesized that there will be a difference of stock price fluctuation between sectors in Indonesia as well. To add a novelty into this research, our main hypothesis is that different kind of event will bring different kind of shock to the existing sectors.

\section{Research Method}

\section{Data}

The data used on his research is a secondary data, consists of daily index of each analyzed sector obtained from Yahoo Finance. The data used is a historical data starting as early as from five working days before the earliest date of the events analyzed up to the five working days after the latest date of the events analyzed. Five working days is chosen as the method to analyze abnormal return due to the close span of the events analyzed on this paper, should this research try to take a broader range of data the result will be too similar due to the close span of the event dates.

This research will be looking at the abnormal return of index prices within eight sectors in Indonesia. The indexes analyzed on this paper are: JKFINA (Financial Index), JKMNFG (Manufacture Index), JKINFA (Infrastructure, Utility \& Transportation), JKAGRI (Agricultural Index), JKCONS (Consumer Goods Index), JKPROP (Construction, Property \& Real Estate), JKBIND (Basic Industry and Chemical Industry), and JKMING (Mining Index). These eight indexes are chosen in order to gain as many insights as possible on how an event can affect the stock price, these indexes are chosen in hope to be able to grasp the condition of many sectors in Indonesia. The observation period starts from March 2020 until the end of April 2020.

\section{Table 1}

\section{Analyzed Events}

\begin{tabular}{lr}
\hline \multicolumn{1}{c}{ Event Name } & $\begin{array}{c}\text { Corresponding } \\
\text { Date }\end{array}$ \\
\hline 1st Confirmed COVID-19 Case & March 2, 2020 \\
1st Confirmed COVID-19 Death & March 11, 2020 \\
Work-From-Home Regulation & March 16, 2020 \\
Flight Restrictions & April 1, 2020 \\
Social Distancing Regulation (PSBB) & April 10, 2020 \\
PSBB Extension & April 22, 2020 \\
Travel Restrictions & April 24, 2020 \\
\hline
\end{tabular}

Listed above on Table 1 is the list of events analyzed in this research. These events are chosen due to up to the point this paper was formulated, this was the events that has already happened. Governmental actions are expected to have both direct and indirect effect on the stock price (Ashraf, 2020a). This research will analyze this seven dates in terms of whether there exists abnormal return or no, to check previous research statement that it is the policies that affected our current economy condition the most (Baker et al., 2020; Smith et al., 2011). Some of previous findings that further gives the reason on why the event is chosen is, during the first death, $72 \%$ of the market reacted negatively (Phan \& Narayan, 2020), and travel ban had shown to reduce mobility that affects productivity $(\mathrm{Gu}$ et al., 2020).

Due to the pandemic is still ongoing, another future research regarding possible future events can also be done in order to grasp the whole condition.

The method used to analyze the change in index price is by calculating the abnormal return of the index with the following formula:

$$
A R=R_{a}-R_{e}
$$

Where $\mathrm{AR}$ is the abnormal return, $R_{a}$ is the index price on the event day, and $R_{e}$ is the expected return of the index calculated by looking at the time span of one year trading data up to five days before the event happened for each events. This approach as well as the formula was taken from previous research by Brounen and Derwall that finds the abnormal returns within the period of terrorism date (Brounen \& Derwall, 2010).

This research uses the span of one-year worth of data leading to five days before the event start for each events in order to be able to calculate the alpha as well as the beta needed to calculate the abnormal return for each events. The alpha and beta of each respective events is calculated by using the slope function as well as the intercept function on Microsoft Excel.

In order to test our first hypothesis, there is a need to show that there exists an abnormal return within the stock price, the abnormal return will be shown by making an adaptation from Brounen and Derwall's (2010) research on calculating the abnormal return as an impact of terrorist attack. On their research, Brounen and Derwall (2010) used the time frame of ten days before and after the attack to show the change between the price in stock which led to the abnormal return at the time of the event. In this research, instead of ten days this research uses five days instead. This is taken into consideration considering that the events happened close to each other, making it possible that should the data is taken for a long period it will interfere the result of one another. By doing this, the abnormal return on days leading to the event and after the event can be shown in order to prove that events within this pandemic situation affects the stock price. 
This analysis will calculate the $A R$ for each sectoral index price in all event in span of eleven days starting from five days before the event starts up until five days after the event occurs. The change in percentage as well as the abnormal return in the IHSG (Indeks Harga Saham Gabungan/Indonesia Composite Stock Price Index) will be shown as well. After compiling the result for all eight sector, by averaging the results of those sectors and then compare it once again with the IHSG abnormal return, a summary can be made to see whether the sectors being analyzed is significant or not.

For the second as well as the last hypothesis the abnormal return result on the event day from seven events will be used to make an average of it in order to get the average abnormal sectoral index price for each sector, the result of those eight sectors will be compared to show the difference between price. This way, the difference between abnormal return of different sectors as well as within different events can be seen.

\section{Dependent Variable}

The dependent variable within this research are the abnormal return score, since this score is determined by the selection of the date when the data is taken as well as which sector the data was taken from. Since the score can result in a different score depending on the constraint taken, the abnormal return score is the dependent variable for this study.

\section{Independent Variables}

As for the independent variables, there are two which includes the event and the business sector. There are many events that happened within this period of pandemic, but seven specific events were chosen based on the potential to show the greatest abnormal return. The chosen date can be controlled and thus it is an independent variable since it does not depend on any other factor. The second one is regarding the business sector. Eight sectoral index was chosen based on the potential to be affected the most by this pandemic condition. The chosen sector can be controlled as well and thus it is an independent variable since it does not depend on any other factor. The control variables within this research is limited to only few variables in order to prevent the suppression effect that might appear by adding too many control variables (Lenz \& Sahn, 2020).

\section{Result and Discussion}

\section{Effect of Pandemic on Stock Prices}

To test the first hypothesis, the price of the stock will be analyzed by checking the abnormal return of the sectoral index price by seeing the actual price and comparing it with the expected price. To find the expected price, one-year historical data up until the time period of five days before the event is used to calculate the alpha and beta of the said event, and calculate the cumulative abnormal return from five days before and after the event happened. The time frame used on this research to find out is relatively small because of the close happening date between events. By this it is hoped that a certain amount of abnormal return near the time period of the event can be seen. Our result is shown Table 2.

Table 2

JKFINA abnormal return

\begin{tabular}{lrrrr}
\hline Event Dates & Alpha & Beta & CAR (-2,2) & CAR (-5,5) \\
\hline March 2, 2020 & 0.000758 & 1.010071 & $-1.995100 \%$ & $-2.121054 \%$ \\
March 11, 2020 & 0.000731 & 1.033394 & $1.332541 \%$ & $0.063445 \%$ \\
March 16, 2020 & 0.000721 & 1.039610 & $0.008641 \%$ & $-3.393346 \%$ \\
April 1, 2020 & 0.000512 & 1.030469 & $-3.964024 \%$ & $-1.414733 \%$ \\
April 13, 2020 & 0.000487 & 1.072743 & $-2.019757 \%$ & $-2.634248 \%$ \\
April 22, 2020 & 0.000304 & 1.063852 & $-3.098434 \%$ & $-6.703939 \%$ \\
April 24, 2020 & 0.000309 & 1.065036 & $-4.885422 \%$ & $-3.198522 \%$ \\
\hline
\end{tabular}

The first result as shown by Table 2 is from the financial sector, it can be seen that negative abnormal returns exists during some period of the events. Despite that, financial sector managed to keep the negative abnormal return numbers into a relatively small number and still manages to be on the positive track in some events. The events that had the most effect on financial sector is when social distancing regulation was implemented (13 April 2020) and was extended (22 April 2020). The Table 2 also shows that first confirmed death in the country do to COVID-19 (11 March 2020) did not really affect the financial sector that much compared to other events. The reason why the financial sector is still going strong at this point of the pandemic might be due to the fact that banks still have their respective reserves to ensure the stability as well as the liquidity during the start of this pandemic. Previous findings also find that although financial sector suffers from a negative effect from previous SARS outbreak, they did not suffer the most loss compared to other sectors (Chen et al., 2007). 
Table 3

JKMNFG Abnormal Return

\begin{tabular}{lrrrr}
\hline \multicolumn{1}{c}{ Event Dates } & \multicolumn{1}{c}{ Alpha } & Beta & CAR (-2,2) & CAR (-5,5) \\
\hline March 2, 2020 & -0.000420 & 1.150889 & $0.790913 \%$ & $1.123879 \%$ \\
March 11, 2020 & -0.000445 & 1.135900 & $1.518072 \%$ & $2.199049 \%$ \\
March 16, 2020 & -0.000428 & 1.125972 & $-0.445622 \%$ & $4.216287 \%$ \\
April 1, 2020 & -0.000235 & 1.138817 & $4.215745 \%$ & $2.777617 \%$ \\
April 13, 2020 & -0.000043 & 1.148853 & $1.594248 \%$ & $0.713118 \%$ \\
April 22, 2020 & 0.000031 & 1.148662 & $5.174158 \%$ & $7.605427 \%$ \\
April 24, 2020 & 0.000033 & 1.147388 & $5.858325 \%$ & $4.453691 \%$ \\
\hline
\end{tabular}

Table 3 contains the result from the manufacturing sector, it can be seen that the manufacturing sector managed to keep themselves out of the negative with only one record of negative cumulative abnormal return during the implementation of work-from-home regulation (16 March 2020). This implies that there might be a shock in productivity due to the newly implemented regulation. Afterwards, manufacture sector managed to gain positive abnormal returns, this might be due to the panic buying that drives people to buy in bulk, especially during the start of the pandemic. The increase is significantly higher during the social distancing regulation extension (13 April 2020) and travel restriction (24 April 2020), indicating that many people are staying at home and they are starting to buy more things. This finding contrasts previous findings that manufacturing industries are the one who felt the biggest impact of COVID-19 (Gu et al., 2020), as well as the finding with previous literature that mentioned that SARS did not have a major impact on the manufacturing industry (Chen et al., 2007). This finding is in line with findings that mentioned that COVID - 19 created opportunities for the manufacturing industries which resulted in manufacturing industries responded positively to COVID-19 (AlAwadhi et al., 2020; He et al., 2020).

Table 4

JKINFA Abnormal Return

\begin{tabular}{lcccr}
\hline Event Dates & Alpha & Beta & CAR (-2,2) & CAR (-5,5) \\
\hline March 2, 2020 & -0.000164 & 1.178781 & $4.454562 \%$ & $6.237172 \%$ \\
March 11, 2020 & -0.000084 & 1.159427 & $0.326345 \%$ & $0.686292 \%$ \\
March 16, 2020 & 0.000010 & 1.174333 & $1.495595 \%$ & $3.234760 \%$ \\
April 1, 2020 & 0.000287 & 1.159747 & $1.720522 \%$ & $-2.029436 \%$ \\
April 13, 2020 & 0.000130 & 1.109044 & $1.561133 \%$ & $4.077796 \%$ \\
April 22, 2020 & 0.000284 & 1.120771 & $0.500369 \%$ & $6.631230 \%$ \\
April 24, 2020 & 0.000296 & 1.118521 & $1.379040 \%$ & $4.798169 \%$ \\
\hline
\end{tabular}

Table 4 contains the result from the infrastructure sector, it can be seen that the infrastructure sector also managed to keep themselves out of the negative with only one record of negative cumulative abnormal return during the implementation of flight restriction (1 April 2020). Infrastructure had gained its peak positive abnormal return during the first announcement of the COVID-19 case in Indonesia, this might due to people's anticipation in infrastructure sector due to many new opportunities such as public sink, disinfectant chambers, as well as other safety regulation tools are about to be created in order to accommodate new safety regulation that will appear on the future.

\section{Table 5}

\section{JKAGRI Abnormal Return}

\begin{tabular}{lccrr}
\hline \multicolumn{1}{c}{ Event Dates } & Alpha & Beta & CAR (-2,2) & CAR (-5,5) \\
\hline March 2, 2020 & -0.000672 & 0.577580 & $-2.346655 \%$ & $-6.389968 \%$ \\
March 11, 2020 & -0.000574 & 0.641292 & $-11.277070 \%$ & $-13.529420 \%$ \\
March 16, 2020 & -0.000575 & 0.623197 & $-8.264991 \%$ & $-16.229065 \%$ \\
April 1, 2020 & -0.000841 & 0.766236 & $-0.766250 \%$ & $7.549455 \%$ \\
April 13, 2020 & -0.00065 & 0.825016 & $2.649591 \%$ & $6.564664 \%$ \\
April 22, 2020 & -0.000466 & 0.836197 & $-5.571645 \%$ & $-3.428028 \%$ \\
April 24, 2020 & -0.000387 & 0.828638 & $-2.561854 \%$ & $-5.882643 \%$ \\
\hline
\end{tabular}

As shown on Table 5, the agricultural sector suffers from mostly negative cumulative abnormal return. Due to the pandemic, the agricultural supply chain had been severely affected. The biggest impact is when the work-from-home regulation (16 March 2020) is implemented. It might be caused by the difficulties to maintain the current agricultural product productivity with the pandemic ongoing. This reflects on the price of the agricultural sector stock as well. This finding was in line with previous research that shows the agricultural industry had suffered from a decline due to COVID-19 (He et al., 2020).

\section{Table 6 \\ JKCONS Abnormal Return}

\section{Event Dates Alpha Beta CAR (-2,2) CAR (-5,5)}

\begin{tabular}{lrrrr}
\hline March 2, 2020 & -0.000892 & 0.995878 & $0.715240 \%$ & $2.204202 \%$ \\
March 11, 2020 & -0.000956 & 1.005927 & $5.923943 \%$ & $4.913304 \%$ \\
March 16, 2020 & -0.000897 & 0.983725 & $-0.225200 \%$ & $7.074782 \%$ \\
April 1, 2020 & -0.000473 & 1.054598 & $3.980463 \%$ & $4.816140 \%$ \\
April 13, 2020 & -0.000049 & 1.117750 & $1.664722 \%$ & $-0.987416 \%$ \\
April 22, 2020 & -0.000086 & 1.109790 & $3.959711 \%$ & $6.821444 \%$ \\
April 24, 2020 & -0.000094 & 1.110648 & $4.294387 \%$ & $3.859008 \%$ \\
\hline
\end{tabular}

Table 6 shows the consumer goods sector, one of the sector that can still go strong during this period of pandemic, due to basic human needs to consume. The abnormal return is significantly stronger during the social distancing regulation implementation (13 April 2020), as people have more time to stay at home, as well as due to the easiness of online shopping nowadays, people's consumption is getting stronger. 
Table 7

\section{JKPROP Abnormal Return}

\begin{tabular}{lccrc}
\hline \multicolumn{1}{c}{ Event Dates } & Alpha & Beta & CAR (-2,2) & CAR (-5,5) \\
\hline March 2, 2020 & 0.000351 & 0.935210 & $-0.133165 \%$ & $-0.342001 \%$ \\
March 11, 2020 & 0.000364 & 0.894756 & $-5.070674 \%$ & $-2.879996 \%$ \\
March 16, 2020 & 0.000311 & 0.882390 & $2.210884 \%$ & $-0.957619 \%$ \\
April 1, 2020 & 0.000070 & 0.808237 & $-6.462770 \%$ & $-6.614898 \%$ \\
April 13, 2020 & -0.000435 & 0.728758 & $-3.011157 \%$ & $-1.727826 \%$ \\
April 22, 2020 & -0.000455 & 0.759260 & $-8.544766 \%$ & $-12.684188 \%$ \\
April 24, 2020 & -0.000507 & 0.763522 & $-8.058541 \%$ & $-10.942516 \%$ \\
\hline
\end{tabular}

Table 7 shows that the property sector is experiencing an even worse negative return compared to other sector, especially during the social distancing regulation period (13 April 2020). This might be due to the current uncertain times property is one of people's least concern. They are most likely spending their resources on basic things such as daily necessities.

\section{Table 8}

\section{JKBIND Abnormal Return}

\begin{tabular}{lrrrr}
\hline \multicolumn{1}{c}{ Event Dates } & Alpha & Beta & CAR (-2,2) & CAR (-5,5) \\
\hline March 2, 2020 & 0.000414 & 1.379430 & $1.480868 \%$ & $0.117313 \%$ \\
March 11, 2020 & 0.000391 & 1.351485 & $-5.248374 \%$ & $-0.369571 \%$ \\
March 16, 2020 & 0.000417 & 1.349119 & $-2.012553 \%$ & $2.741018 \%$ \\
April 1, 2020 & 0.000339 & 1.284342 & $8.904424 \%$ & $4.300134 \%$ \\
April 13, 2020 & 0.000304 & 1.206155 & $2.240758 \%$ & $6.154066 \%$ \\
April 22, 2020 & 0.000771 & 1.234151 & $9.657185 \%$ & $12.389564 \%$ \\
April 24, 2020 & 0.000827 & 1.227534 & $10.836499 \%$ & $7.981633 \%$ \\
\hline
\end{tabular}

Basic industry and chemical sector as shown by Table 8 supplies basic materials in order to be processed. While it shows that during several events this sector had gained negative, on some events positive abnormal return can be seen as well. This might be due to the items being sold within this industry is a necessity to answer the rise of consumption during the pandemic period, this is consistent with the fact found earlier in this research that the consumer goods industry as well as the infrastructure sector had gained positive abnormal return as well.

\section{Table 9}

\section{JKMING Abnormal Return}

\begin{tabular}{lrrrr}
\hline \multicolumn{1}{c}{ Event Dates } & Alpha & Beta & CAR (-2,2) & CAR (-5,5) \\
\hline March 2, 2020 & -0.000871 & 0.710039 & $-0.822967 \%$ & $-1.940255 \%$ \\
March 11, 2020 & -0.000814 & 0.744945 & $-4.895272 \%$ & $-3.457011 \%$ \\
March 16, 2020 & -0.000855 & 0.735799 & $-2.013718 \%$ & $0.073480 \%$ \\
April 1, 2020 & -0.000791 & 0.753705 & $1.921629 \%$ & $4.011724 \%$ \\
April 13, 2020 & -0.000760 & 0.703788 & $1.052859 \%$ & $2.952719 \%$ \\
April 22, 2020 & -0.000505 & 0.714433 & $-2.376835 \%$ & $-3.823897 \%$ \\
April 24, 2020 & -0.000482 & 0.714886 & $-1.813321 \%$ & $-2.916539 \%$ \\
\hline
\end{tabular}

Table 9 shows that mining sector suffers the biggest negative abnormal return during the announcement of first death due to COVID-19, this might be due to the concern of the future performance of mining industry due to the uncertainty on COVID19 that might causes decrease on demand for mining products. This is also in line with previous findings in China that mentioned the mining industry is one of the industries that suffered more from the impact compared to other industries (Gu et al., 2020; He et al., 2020).



Figure 1. $1^{\text {st }}$ event

11 March 2020 - 1st Confirmed COVID-19 Death

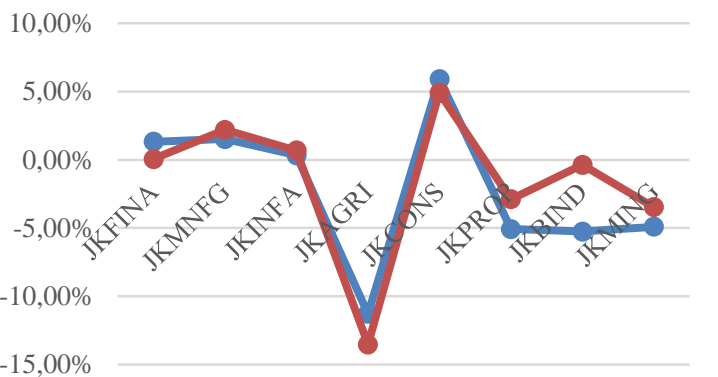

$\longrightarrow$ CAR $(-2,2) \longrightarrow C A R(-5,5)$

Figure 2. $2^{\text {nd }}$ event

16 March 2020 - Work-From-Home Regulation



Figure 3. $3^{\text {rd }}$ event 


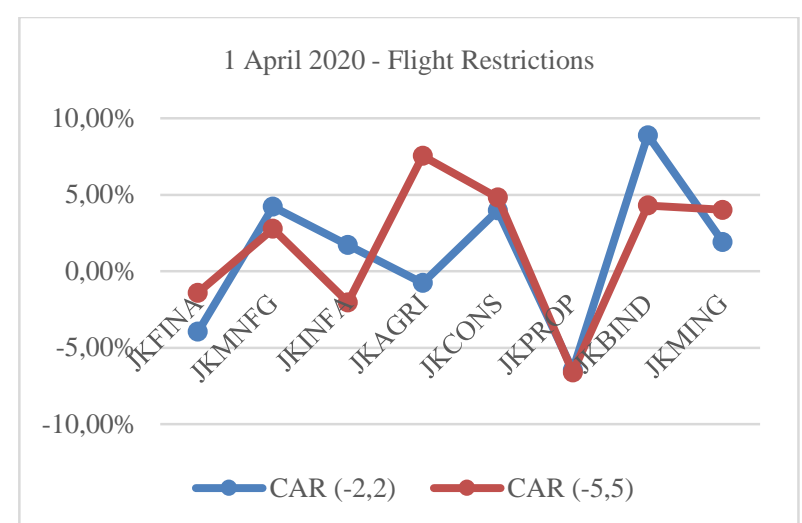

Figure 4. $4^{\text {th }}$ event

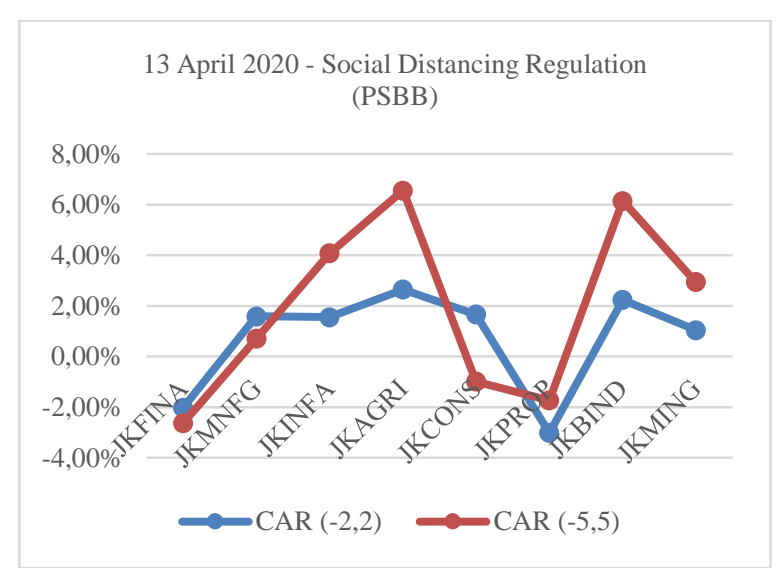

Figure 5. $5^{\text {th }}$ event

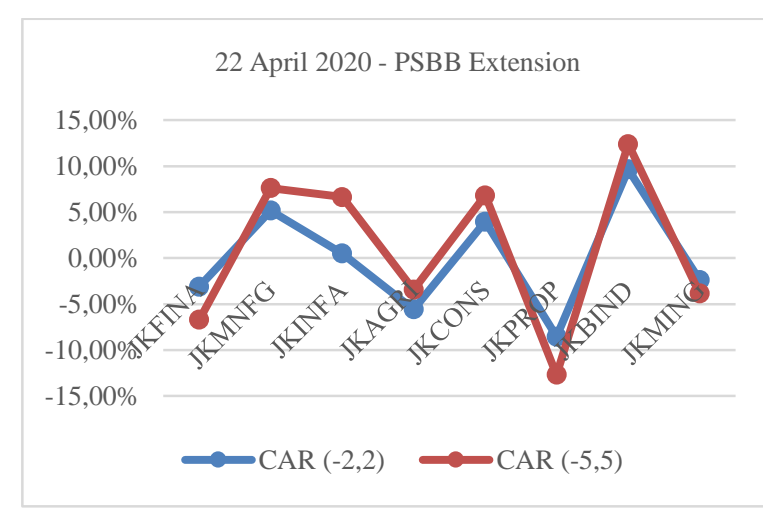

Figure 6. $6^{\text {th }}$ event



Figure $7.7^{\text {th }}$ event
As shown on Figure 1, the abnormal return for each sector is not yet significant, this might be due to the fact that this event is the gateway to another event, it all started with the $1^{\text {st }}$ confirmed case within the country. There is some abnormal return during this event, due to the announcement of the $1^{\text {st }}$ confirmed case, the Indonesian composite index drops by $1.68 \%$ (Widiantoro, 2020).

On Figure 2, it can be seen that the abnormal return is significantly showing, agricultural sector suffered the most loss compared to other sectors, this might be caused by the uncertainty that this pandemic was about to bring, it is inevitable that government are going to take countermeasures against this pandemic, thus there might be a need to address some changes within the agricultural sector productivity. This is in line with previous findings that find out that agricultural sector was one of the sectors that suffered from a loss (He et al., 2020). This graph also starts to shows that the manufacturing sector is slowly gaining abnormal return due to the future opportunities that will be beneficial to the manufacturing industry. The consumer goods sector gained the most profit from this event, this might be caused by the fear of COVID-19 that drives people to do panic buying of consumable things such as food caused by expectation about COVID-19 as well as herd psychology (Wang \& Hao, 2020).

On Figure 3, it can be seen that the agricultural sector suffered more loss, this might be caused by the difficulties to maintain the current agriculture sector productivity. Manufacturing sector, consumer goods sector, and infrastructure sector continues to gain positive abnormal returns, this is in line with previous research as manufacturing sector gained many opportunities from the current pandemic (Al-Awadhi et al., 2020; He et al., 2020) and might still be driven by the herd psychology mentioned before (Wang \& Hao, 2020).

On Figure 4, it can be seen that the basic industry sector as well as the agricultural sector managed to gain positive abnormal return compared to the past events, in case of basic industry, it might be caused by the necessity for basic materials needed to produce goods, as for the agricultural sector it might be caused by people's necessity as well, as the agricultural sector contributes to the daily consumption of the people as well.

On Figure 5, it can be seen that the agricultural sector and the basic industry sector is still going strong, this might be caused by the impact of government help towards the agricultural industry in form of leniency of KUR (Kredit Usaha Rakyat) implemented earlier that month (CNN, 2020), while other industry stays relatively the same as the previous event. 
On Figure 6, it can be seen that the basic industry sector is still going strong while agriculture sector returns to the negative, this might be caused by the drop of crude palm oil price which ultimately impacts Indonesian agricultural exports (Setiaji, 2020). While sectors such as manufacturing and infrastructure continues to gain even more positive abnormal return due to the social distancing period being extended as well as the opportunity to create public health measures.

On Figure 7, it can be seen that the trend is still relatively the same compared to previous event, this might be caused by the event date between Figure 6 and Figure 7 is relatively close.

In overall, based on the explanation above, there are real relationships between the current pandemic events and its impact to the industry performance in Indonesia. After seeing the results, it can be concluded that during a specific event, reactions from each sector resulted in different kind of response on different sectors. There are sectors who respond positively to an event and there are sectors who respond negatively on an event. The difference between sector plays a big role in determining whether COVID-19 brings profit to them or not.

\section{Discussion}

This paper analyzes the effect of events in form of governmental announcement as well as governmental regulations to the stock price of several sectors within Indonesia. From this paper, it is known that there are sectors that are facing difficulties within this pandemic. In case of Indonesia, it is found that the impact of the pandemic is similar towards what is happening to other sectors based on previous research findings (Al-Awadhi et al., 2020; Gu et al., 2020; He et al., 2020).

It is found that there are sectors that gains positive abnormal return due to the pandemic and there are sectors that gains negative abnormal return as well. The manufacturing sector is one of the sectors that managed to gain positive abnormal return, this might be caused by the implementation of the work-fromhome regulation, people are staying more at home and have more time to buy things, as well as the uncertainty of the situation made people starting to buy things in bulk. This finding is also in line with several of the previous findings (Al-Awadhi et al., 2020; He et al., 2020), but interestingly contrasts another findings that states that manufacturing industries were the one who felt the biggest impact of COVID-19 (Gu et al., 2020). The infrastructure sector also managed to score a positive abnormal return, this might be driven by the needs of new infrastructure that accommodates the health regulation such as public sink, as well as other social distancing equipment. The consumer goods sector also managed to gain a positive abnormal return which may be caused due to the fact that even within this pandemic people still need to buy foods as well as other necessity in order to live, as well as the easiness of getting items nowadays due to the advancement of technology.

One of the sector who suffers from negative abnormal return is the property sector, this might be due to the fact that when the condition is uncertain, people will prioritize their basic necessity first rather than thinking about investing in property. The next sector that suffers from negative abnormal return is the agricultural sector, this might be driven by the disruption that the regulations implemented causes a change in the production process that drives down productivity, this finding was in line with previous findings as well (He et al., 2020). And lastly the sector that suffers from negative abnormal return is the mining sector, which might be caused by the same reason the agricultural sector suffers from, the regulations implemented causes a change in the production process which affects the productivity, this is also in line with previous findings in China that mentioned the mining industry is one of the industries that suffered more from the impact compared to other industries ( $\mathrm{Gu}$ et al., 2020; He et al., 2020).

Ideally, this research would prove a better and a more through result should this research is conducted after the COVID-19 pandemic is over, but with the current data available it is enough to create an initial research regarding this matter. It is hoped that by analyzing this subject, this research can contribute into the ever-growing study regarding financial instruments as well as factors that can affect them, as well as to educate people regarding the implication that a pandemic might bring into financial area.

Also, as mentioned earlier, this research also did not count for any possible confounding bias. According to previous research there are three criteria for a variable to be considered as a confounder which are: 1 . The variable have to have an association with the disease, 2. It must be associated with the exposure, and 3. It must not be an effect of the exposure (Jager, Zoccali, MacLeod, \& Dekker, 2008). In this research case, there are lots of unknown internal and external variables that can cause bias such as the company's internal condition, as well as the pressure from the public, and not all of them are measurable, leaving this spot open for a discussion for future research. 


\section{Conclusion and Implications}

This research is designed to prove previous research result that mentioned that the biggest factor on why COVID-19 had an impact that is not comparable to previous diseases is because of the human themselves, specifically in form of governmental regulations which dictates what to do and what to not do during this pandemic. This paper translates those governmental regulations as well as government announcement into events in which those events are being used as a variable in order to test the abnormal return on stocks that might happen as a response to those events. After all eight sectors is analyzed, it is found that the impact of this pandemic differs from one sector to another, the one who suffers loss the most during this pandemic is the agricultural sector, property sector, and the mining sector, this might be because of in this pandemic situation, people will not think much about buying property and prioritize their livelihood by getting daily necessities that is harder to get in this situation, as for the agricultural and the mining sector, the applied regulations as well as announcements may hinder the productivity thus leading to a loss. For the financial sector, they are experiencing loss as well, but the loss is not that high compared to what the previous sectors had experienced, this might be due to the fact that financial sectors have its own reserves when it comes to facing this unpredictable condition. As for the sectors that gained positive abnormal returns during this period includes the basic industry sector, the manufacturing sector, the infrastructure sector, as well as the consumer goods sector. The basic industry sector, the consumer goods sector as well as the manufacturing sector might be gaining profit due to the increase of people's consumption, be it due to panic buying or due to them spending more time at home due to the regulations. While the infrastructure sector also gained an opportunity from many possible new public health regulation projects.

It is hoped that this paper can serve as an information for the government to help them creating policies that can provide appropriate assistance towards industries and firms that are experiencing difficulties. There are sectors who is highly affected from the policy implementation as well as announcement from the government, in order for this decline to stop, there might be a need to address these industries and formulate a plan on how to make these industries thrive. The government will also need to think about the long-term impact of the pandemic.

\section{References}

Al-Awadhi, A. M., Alsaifi, K., Al-Awadhi, A., \& Alhammadi, S. (2020). Death and contagious infectious diseases: Impact of the COVID-19 virus on stock market returns. Journal of Behavioral and Experimental Finance, 27, 100326. https://doi.org/10.1016/j.jbef.2020. 100326

Ali, M., Alam, N., \& Rizvi, S. A. R. (2020). Coronavirus (COVID-19) - An epidemic or pandemic for financial markets. Journal of Behavioral and Experimental Finance, 27, 100341. https://doi.org/10.1016/j.jbef.2020.100341

Ardan, M., Rahman, F. F., \& Geroda, G. B. (2020). The influence of physical distance to student anxiety on COVID-19, Indonesia. Journal of Critical Reviews, 7(17), 1126-1132. https://doi. org/0.31838/jcr.07.17.14 1

Ashraf, B. N. (2020a). Economic impact of government interventions during the COVID-19 pandemic: International evidence from financial markets. Journal of Behavioral and Experimental Finance, 27, 100371. https://doi.org/10.1016/ j.jbef.2020.100371

(2020b). Stock markets' reaction to Covid-19: Moderating role of national culture. Finance Research Letters, 101857. https://doi. org/0.1016/j.frl.2020.101857

Avalos, F., \& Zakrajšek, E. (2020). Covid-19 and SARS: What do stock markets tell us? Retrieved from: https://www.bis.org/publ/qtrpdf/r_qt2003w. htm

Bai, L., Wei, Y., Wei, G., Li, X., \& Zhang, S. (2020). Infectious disease pandemic and permanent volatility of international stock markets: A longterm perspective. Finance Research Letters, 101709. https://doi.org/1 0.1016/j.frl.2020.101709

Baker, S., Bloom, N., Davis, S., Kost, K., Sammon, M., \& Viratyosin, T. (2020). The unprecedented stock market impact of COVID-19. Retrieved from: https://doi.org/10.3386/w2 6945

Barone, A. (2019). Understanding abnormal return avoids surprises. Retrieved from: https://www. investopedia.com/terms/a/abnormalreturn.asp

Barro, R., Ursúa, J., \& Weng, J. (2020). The coronavirus and the great influenza pandemic: Lessons from the "Spanish Flu" for the coronavirus's potential effects on mortality and economic activity. Retrieved from: http s://www. nber.org/system/files/working_papers/w26866/ w26866.pdf. https://doi.org/1 0.3386/w26866

Brounen, D., \& Derwall, J. (2010). The impact of terrorist attacks on international stock markets. 
European Financial Management, 16 (4), 585598. https://doi.org/10.1111/j.146 8-036X.2009. 00502.x

Burdekin, R. C. K. (2020). Death and the stock market: International evidence from the Spanish Flu. Applied Economics Letters. https://doi.org/10. 1080/13504851.2020.1828802.

Chen, M. H., Jang, S. C. (Shawn), \& Kim, W. G. (2007). The impact of the SARS outbreak on Taiwanese hotel stock performance: An eventstudy approach. International Journal of Hospitality Management, 26(1), 200-212. https://doi. org/10.1016/j.ijhm.2005.11.004

Chesney, M., Reshetar, G., \& Karaman, M. (2011). The impact of terrorism on financial markets: An empirical study. Journal of Banking and Finance, 35(2), 253-267. https ://doi.org/10.1016/j.jbankfin.2010.07.026

CNN. (2020). Realisasi KUR baru 32,15 persen hingga April 2020. Retrieved from: https:// www.cnnindonesia.com/ekonomi/20200618083 507-78-514588/realisasi-kur-baru-321 5-persenhingga-april-2020

Corbet, S., Gurdgiev, C., \& Meegan, A. (2018). Longterm stock market volatility and the influence of terrorist attacks in Europe. Quarterly Review of Economics and Finance, 68, 118-131. https://doi. org/10.1016/j.qref. 2017.11.012

Dure, E. (2020). The history of pandemics and stock markets. Retrieved from: https://ww w.investopedia.com/the-history-of-pandem ics-and-stockmarkets-5093256

Fama, E. F. (1970). Efficient capital markets: A review of theory and empirical work. The Journal of Finance, 25(2), 383-417. https://doi.org/10. 2307/2325486

Gu, X., Ying, S., Zhang, W., \& Tao, Y. (2020). How do firms respond to COVID-19? First evidence from Suzhou, China. Emerging Markets Finance and Trade, 56(10), 2181-2197. https://doi.org/ 10.1080/1540496X.20 20.1789455

He, P., Sun, Y., Zhang, Y., \& Li, T. (2020). COVID19 's impact on stock prices across different sectors-An event study based on the Chinese Stock Market. Emerging Markets Finance and Trade, 56(10), 2198-2212. https://doi.org/10. 1080/1540496X.20 20.1785865

History.com, E. (2020). Pandemics that changed history: Timeline - HISTORY. Retrieved from: https://www.history.com/topics/middleages/ pandemics-timeline

Jager, K. J., Zoccali, C., MacLeod, A., \& Dekker, F. W. (2008). Confounding: What it is and how to deal with it. Kidney International, 73(3), 256260. https://doi.org/10.1038/sj. ki.5002650
Ji, Q., Zhang, D., \& Zhao, Y. (2020). Searching for safe-haven assets during the COVID-19 pandemic. International Review of Financial Analysis, 71, 101526. https://doi.org/10.1016/j.irfa.2020. 101526

Jiang, Y., Zhang, Y., Ma, C., Wang, Q., Xu, C., Donovan, C., Ali,G., Xu, T., \& Sun, W. (2017). H7N9 not only endanger human health but also hit stock marketing. Advances in Disease Control and Prevention, 2 (1), 1-7. https://doi.org/10. 25196/adcp201711

Karolyi, G. A. (2011). The consequences of terrorism for financial markets: What do we know? SSRN Electronic Journal. https://doi.org/10.2139/ssrn. 904398

Kelly, L. (2020). Australia tightens social distancing rules to fight coronavirus. Reuters. Retrieved from: https://www.reuters.com/arti cle/us-healthcoronavirus-australia/australia-tightens-socialdistancing-rules-to-fight-coronavirus-idUSKB N21F01N

Lagoarde-Segot, T., \& Leoni, P. L. (2013). Pandemics of the poor and banking stability. Journal of Banking and Finance, 37(11), 4574-4583. https://doi.org/10.1016/j.jbankfin.2 013.04.004

Lango, L. (2020). How 5 pandemics before coronavirus impacted the stock market. Investorplace. https://investorplace.com/2020/03/how-5-pandemics-before-coronavirus-impacted-the-stockmarket/

Lenz, G. S., \& Sahn, A. (2020). Achieving statistical significance with control variables and without transparency. Political Analysis, 1-14. https://doi. org/10.1017/pan.2020.31

Madhav, N., Oppenheim, B., Gallivan, M., Mulembakani, P., Rubin, E., \& Wolfe, N. (2017). Pandemics: Risks, impacts, and mitigation. In D. T. Jamison, H. Gelband, S. Horton, P. Jha, R. Laxminarayan, C. N. Mock, \& R. Nugent (Eds.), Disease control priorities: Improving health and reducing poverty, third edition, volume 9 (pp. 315 -345). Washington, DC: The World Bank.

Mensbrugghe, D. V. D., Timmer, H., \& Burns, A. (2006). Evaluating the economic consequences of avian influenza. The World Bank. Retrieved from: https://agris.fao.org/agris-search/search. do?recordID=US2012416845

Muradoğlu, Y. G., \& Sivaprasad, S. (2012). Capital structure and abnormal returns. International Business Review, 2l(3), 328-341. https://doi.org/ 10.1016/j.ibusrev.2011.03.007

Nadhifah, A. (2020). 4 reasons why you should look to Indonesia to expand your business. Retrieved from: https://www.techinasia.com/4-reasonsindonesia-expand-business. 
Nikkinen, J., \& Vähämaa, S. (2010). Terrorism and stock market sentiment. Financial Review, 45(2), 263-275. https://doi.org/10.1111/j.1540-6288. 2010.00246.x

Nippani, S., \& Washer, K. M. (2004). SARS: A nonevent for affected countries' stock markets? Applied Financial Economics, 14(15), 11051110. https://doi.org/10.1080/09603100420003 10579

Phan, D. H. B., \& Narayan, P. K. (2020). Country responses and the reaction of the stock market to COVID-19 - A preliminary exposition. Emerging Markets Finance and Trade, 56(10), 21382150. https://doi.org/10.1080/1540496X.2020. 1784719

Ross, S., Westerfield, R., \& Jaffe, J. (2012). Corporate finance. Tenth Edition. New York, NY: McGraw-Hill Education.

Salisu, A. A., Sikiru, A. A., \& Vo, X. V. (2020). Pandemics and the emerging stock markets. Borsa Istanbul Review, 20(1), S40-S48. https://doi.org/10.1016/j.bir.2020.11.004

Setiaji, H. (2020). Ambyar! Harga CPO anjok hampir 6\%, saham agrikultur ambrol 8\%. Cnbcindonesia.com. Retrieved from: https: //www.cnbcindonesia.com/market/20200426000913-17154463/ambyar-harga-cpo-anjok-hampir-6saham-agrikultur-ambrol-8

Setyawan, F. E. B., \& Lestari, R. (2020). Challenges of stay-at-home policy implementation during the coronavirus (COVID-19) pandemic in Indonesia. Jurnal Administrasi Kesehatan Indonesia, 8(0), 15-20. https://doi.org/10.20473/JAKI.V8I0.2020. 15-20

Smith, R. D., Keogh-Brown, M. R., \& Barnett, T. (2011). Estimating the economic impact of pandemic influenza: An application of the computable general equilibrium model to the UK. Social Science and Medicine, 73 (2), 235244. https://doi.org/10.1016/j.socscimed.2011. 05.025

Smyth, C. (2020). New 'social distancing' rules as Covid-19 is declared a pandemic. The Times. Retrieved from: https://www.thetimes.co.uk/ article/new-social-distancing-rules-as-covid-19is-declared-a-pandemic-p7t3 mxscn

Sorescu, A., Warren, N. L., \& Ertekin, L. (2017). Event study methodology in the marketing literature: An overview. Journal of the Academy of Marketing Science, 45(2), 186-207. https://doi.org/ 10. 1007/s11747-017-0516-y

Susilawati, S., Falefi, R., \& Purwoko, A. (2020). Impact of COVID-19's pandemic on the economy of Indonesia. Budapest International Research and Critics Institute (BIRCI-Journal): Humanities and Social Sciences, 3(2), 11471156. https://doi.org/10.33258/ birci.v3i2.954

Taylor, B. (2020). The Spanish flu and the stock market: The pandemic of 1919. Retrieved from: https://www.globaltrademag.com/th e-spanishflu-and-the-stock-market-the-pandemic-of-1919/

Wang, H. H., \& Hao, N. (2020). Panic buying? Food hoarding during the pandemic period with city lockdown. Journal of Integrative Agriculture, 19(12), 2916-2925. https://doi.org/10.1016/ S2095-3119(20)63448-7

Widiantoro, D. W. (2020). IHSG jatuh ke level 5. 361 Kompas.id. https://kompas.id/baca/ekonomi/ 2020/03/02/ihsg-jatuh-ke-level-5-361

Zhang, D., Hu, M., \& Ji, Q. (2020). Financial markets under the global pandemic of COVID-19. Finance Research Letters, 36, 101528. https://doi.org/10.1016/j.frl.2020.1015 28. 